\title{
Plant germline development: a tale of cross-talk, signaling, and cellular interactions
}

\author{
Ueli Grossniklaus
}

Published online: 18 May 2011

(C) Springer-Verlag 2011

Plants have a complex life cycle in which diploid and haploid generations alternate: the diploid sporophyte produces the spores, while the haploid gametophytes form the gametes. In bryophytes and ferns, the dimorphic gametophytes are free-living, but their development has become dependent on the sporophyte in seed plants. This opens a multitude of opportunities for interactions and cross-talk between the two generations, many of which are discussed in this issue of Sexual Plant Reproduction. In angiosperms, gametophytes develop within the reproductive organs of the flower: the male gametophyte (pollen) within the anthers and the female gametophyte (embryo sac) within the ovule, which develops from the placental tissues of the carpel (Ma and Sundaresan 2010). The gametophytes in turn differentiate one pair of gametes each. During double fertilization, which initiates seed development, one sperm fuses with the central cell producing the endosperm, while the second fertilizes the egg to form the embryo and thus the next sporophyte generation.

Although Theophrastus of Eresos (371-287 BC), the 'Father of Botany', already recognized the existence of male and female plants (Negbi 1995), it took the offering of a prize by the Imperial Academy of Sciences in St. Peterburg, to experimentally prove that plants reproduce sexually just as animals do. By crossing Nicotiana rustica with N. paniculata, Josef Gottlieb Kölreuter (1761) obtained viable hybrids with characteristics of both parents, foreshadowing the genetic work of Gregor Mendel. Kölreuter's experiments unambiguously demonstrated that

U. Grossniklaus $(\bowtie)$

Institute of Plant Biology and Zürich-Basel Plant Science Center, University of Zürich, Zollikerstrasse 107, 8008 Zürich, Switzerland

e-mail: grossnik@botinst.unizh.ch both parents contribute to the offspring, refuting preformationist theories. It was a long way from these early days to the unraveling of the genetic basis underlying sexual reproduction, but the genetic approaches applied over the last 15 years have been instrumental in shedding light onto the molecular basis of reproduction as presented in this issue. While most of the genetic work was done using Arabidopsis thaliana as a model system, experimental approaches in Zea mays and Torenia fournieri have also greatly contributed to our understanding of reproductive development at the molecular level (Dresselhaus et al. 2011; Okuda and Higashiyama 2010).

Studies over the last years have made it clear that cellular communication and signaling events play many crucial roles during plant reproduction. Although the first molecular players in such interactions have only recently been uncovered (e.g., Márton et al. 2005; Escobar-Restrepo et al. 2007; Okuda et al. 2009; Kessler et al. 2010), the important role of cellular communication may have been anticipated given the close proximity and intimate interactions between the developing gametophytes and surrounding sporophytic tissues, between the constituent cells of the gametophytes, and between male and female gametophytes and gametes during double fertilization. Furthermore, it has also become evident that epigenetic processes, in particular gene regulation mediated by short interfering RNAs (siRNAs) and micro RNAs (miRNAs), play crucial roles in reproductive development. Many putative signals such as hormones and secreted peptides are mobile, including siRNAs and miRNAs (Chitwood and Timmermans 2010). This opens possibilities for maternal and paternal effects not only on seed development but also on gametogenesis. Signals produced by sporophytic tissues may influence the development of male or female gametophytes or the embryo and/or endosperm following 
fertilization. Alternatively, factors stored in progenitor cells, e.g., male and female gametes but also micro- and megaspore mother cells, may influence the subsequent development of the fertilization products and gametophytes, respectively.

To distinguish the different origins of such parental effects, it may be appropriate to separate them into those effected by the sporophyte (sporophyte-dependent), which are non-cell-autonomous, and those effected by the reproductive lineage (germline-dependent), which may rely on stored products or epigenetic modifications inherited by the daughter cells (e.g., Pillot et al. 2010). Conceptually, this corresponds to the situation in Drosophila melanogaster, where both soma-dependent and germline-dependent maternal effects are essential for normal oogenesis (Bastock and St Johnston 2008). However, plants do not have a germline that is set-aside early during embryonic development as animals do, and different definitions for the plant germline exist. Here, the germline is considered to be determined as soon as a cell is committed to produce gametes. Thus, the archesporial cells, which give rise to micro- and megaspore mother cells, are the first specified cells of the germline; but others have placed this event later, during gametophyte development (Twell 2011, this issue). The separation of sterile somatic cells from germline cells that contribute to the next generation has been of interest to developmental and evolutionary biologists since this distinction was first made over a century ago (Weismann 1893). Chlorophyta (green algae), a sister clade to the Streptophyta containing the land plants, are particularly well suited to address the evolution of multicellularity and the separation of germline and soma, as they span the full range of organizational complexity, ranging from unicellular to colonial species and ultimately to multicellular species with separated soma and germline (Hallmann 2011, this issue).

In the ovule of flowering plants, the germline is established once a subepidermal cell is specified as archesporial cell, which-either after division or directly-forms the megaspore mother cell committed to meiosis. In most angiosperms including Arabidopsis and maize, usually only a single subepidermal cell enters this developmental pathway, although several cells have the potential to do so (Grossniklaus and Schneitz 1998). This potential is revealed in mutants such as multiple archesporial cells1 in maize (Sheridan et al. 1996) or multiple sporocytel in rice (Nonomura et al. 2003), which affect signaling pathways involved in lateral inhibition mechanisms that prevent more than one cell from differentiating into a megaspore mother cell (reviewed in Armenta-Medina et al. 2011, this issue). Recently, it was shown that the activity of a siRNA pathway involving ARGONAUTE9 (AGO9), which is expressed in cells surrounding the megapore mother cell, is also involved in the restriction of germline fate (OlmedoMonfil et al. 2010). In ago9 mutants, multiple cells enlarge similar to the megaspore mother cell and can initiate gametophyte development, likely without undergoing meiosis. In contrast, dominant mutations in maize AGO104 act in the megaspore mother cell and cause the production of unreduced female gametophytes (Singh et al. 2011). These findings illustrate the importance of siRNA-based mechanisms in specifying germline fate and suggest that their modulation may be involved in generating the diverse reproductive modes found in sexual and apomictic plants, the latter reproducing asexually through seeds (ArmentaMedina et al. 2011, this issue). The subsequent development of the female gametophyte also depends on signals from the sporophytic tissues of the ovule (Bencivenga et al. 2011, this issue). This is evidenced by the fact that many mutants affecting the development of the sporophytic tissues of the ovule disrupt female gametophyte development. Although no cytological abnormalities are seen in sporophytic ovule tissues if the embryo sac is absent, signaling from the female gametophyte to the sporophyte is revealed at the level of gene expression (Johnston et al. 2007). It is likely that phytohormones play a role in the cross-talk between the two generations and deciphering their exact roles is a topic of current investigations (Bencivenga et al. 2011, this issue).

The development of male and female gametophytes, starting with the mitotic division of micro- and megaspores, is a complex process involving the establishment of polarity, coordinated divisions, nuclear migrations, cell specification, and differentiation. Using genetic and molecular approaches, a few of the molecular components controlling these processes have been identified over the last decade. Although the gametophyte is no longer the 'forgotten generation' (Heslop-Harrison 1979), we are far from a complete understanding of their development and function. But an excellent framework of cytological and ultrastructural investigations performed in the last century (Johri 1985) allowed the integration of new cell biological observations. The female gametophyte develops from the functional megaspore through three syncytial divisions forming an 8-nucleate embryo sac. After cellularization, typically seven cells are formed (Polygonum type): two synergids and an egg cell at the microylar pole, the binucleate central cell in the middle, and three antipodals at the chalazal pole (Sprunck and Groß-Hardt 2011, this issue). The polar axis of the developing female gametophyte is established in alignment with the chalazalmicropylar axis of the ovule but the underlying mechanisms are not understood. It is likely that cytoskeletal components are important for the determination of polarity and also play a role in positioning the nuclei within the embryo sac. The latter is crucial for cell specification, as mispositioned 
nuclei adopt a different cell fate, likely influenced by cytoplasmic determinants that are localized to specific regions of the syncytial embryo sac (Sprunck and GroßHardt 2011, this issue).

Similar events also occur during male gametophyte development, where an initially symmetric microspore becomes polarized and divides asymmetrically to form a large vegetative and a small generative cell (Twell 2011, this issue). The generative cell divides once more to form the two sperm cells that will participate in double fertilization. Recently, sperm cells were found to harbor a much more diverse transcriptome than anticipated, which can also influence the next sporophyte generation (Borges et al. 2008; Gou et al. 2009; Russell et al. 2010). Polarity establishment and maintenance in the microspore depends on cytoskeletal components, in particular microtubules, and is required for asymmetrical division, which initiates cellular differentiation. In the male gametophyte, cell fate specification is intimately connected to cell cycle progression, whose control has been unraveled, in some detail, at the molecular level. In addition, epigenetic regulation and siRNA pathways play an important role in maintaining genome integrity of the gametes (Twell 2011, this issue). It has been proposed that siRNAs produced in the vegetative cell are responsible for silencing transposable elements in the sperm cells (Slotkin et al. 2009). Similarly, the siRNA pathway involving AGO9 in the ovule described above plays a role in silencing transposons in the embryo sac (Olmedo-Monfil et al. 2010). In both cases, the siRNAs are proposed to act non-cell-autonomously, but the mechanisms by which this can be achieved are currently not known.

Of particular interest is how the four cell types of the mature female gametophyte are determined. Although our understanding of this process is still fragmentary, several mutants that affect cell specification have been described over the last few years (Sprunck and Groß-Hardt 2011, this issue). Based on the observation that a manipulation of auxin production or response in the female gametophyte can alter cell fate, it was proposed that an auxin gradient may determine distinct cell fates along the axis of the embryo sac (Pagnussat et al. 2009). How this auxin gradient is established and maintained, and how it specifies cell fate, is currently not clear. Part of the known molecular machinery, possibly acting downstream of auxin, includes transcription factors involved in specifying egg cell (Pagnussat et al. 2007; Köszegi et al. 2011) and synergid cell fate (Steffen et al. 2008; Bemer et al. 2008). Moreover, non-cell-autonomous signaling events including lateral inhibition, which prevents accessory cells from adopting gametic cell fate (Groß-Hardt et al. 2007), and the induction of cell death in the antipodals (Kägi et al. 2010), have been uncovered. In summary, the study of mutants affecting the specification and differentiation of the cell types in the female gametophyte has uncovered an important role of cell-to-cell communication and revealed an unexpected developmental plasticity allowing these cells to respond to altered signals (Sprunck and Groß-Hardt 2011, this issue).

Once the gametophytes have reached maturity, they must interact to achieve double fertilization. This involves the guidance of the pollen tube to the micropyle, achieved by chemotactic signals produced by the synergids, and pollen tube reception, an active process leading to pollen tube rupture and sperm release, also controlled by the synergids (Sprunck and Groß-Hardt 2011, this issue). Interestingly, pollen tube guidance and reception relies on secreted peptides and signal transduction components that are related to proteins involved in defense mechanisms (Amien et al. 2010; Dresselhaus and Márton 2009).

After successful fertilization, the embryo constitutes the next sporophyte generation. The zygote shares the same axis of polarity as the egg cell, which contains a micropylarly localized vacuole and a chalazally positioned nucleus. After fertilization the zygote elongates along this axis and divides asymmetrically, producing a small apical and a larger basal cell, the founder cells of the embryonic and suspensor lineages, respectively (Zhang and Laux 2011, this issue). Although the polar axes of the ovule, embryo sac, egg cell, and zygote likely depend one on the other, the molecular mechanisms determining this polarity are completely unknown. In Arabidopsis, the elongation of the zygote depends on a signaling cascade initiated by a paternally provided factor, SHORT SUSPENSOR, which is delivered by the sperm's cytoplasm in the form of mRNA and translated in the zygote after fertilization (Bayer et al. 2009). This paternal effect ensures that cell elongation and asymmetric division can only occur after fertilization, but this mechanism is obviously circumvented in apomictic species where embryogenesis occurs in the absence of fertilization (Grossniklaus 2009). Subsequent development and patterning of the embryo involves the polarization of dynamic auxin signaling and the restricted expression of transcription factors that specify cell lineages (Zhang and Laux 2011, this issue). Moreover, maternally provided factors including siRNAs were recently found to play a crucial role in the regulation of gene expression during early stages of embryo development (Autran et al. 2011). Taken together, these findings illustrate the importance of germline-dependent maternal and paternal effects on embryogenesis.

Although genetic and molecular studies have led to unprecedented progress in our understanding of plant germline development over the last decade, we have only seen a glimpse of the fascinating but complex cellular processes that underlie successful seed formation. It has 
become evident that a multitude of cellular interactions, signaling processes, and cross-talk between sporophyte and gametophytes play a central role in reproduction. Many of the developmental processes reviewed in this issue of Sexual Plant Reproduction involve siRNA pathways, and it will be of great interest to unravel how they regulate cellular functions and affect the behavior of neighboring cells. A deeper understanding of polarity establishment and cell specification will require the analyses of gene expression and regulation, not only at the cellular level, but also within subdomains of a cell. Recent advances using laser-assisted microdissection for transcript profiling (Wuest et al. 2010) should allow the analysis of specific subcellular regions, for instance the chalazal and micropylar domains of the developing syncytial female gametophyte or the basal and apical halves of the zygote. Finally, most studies, to date, are based on fixed material and analysis at specific time points. We have only just begun to study plant reproduction using life cell imaging (Hamamura et al. 2011), which bears tremendous promise, despite the substantial technological hurdles that have to be taken. Certainly, the application of new technologies will revolutionize the way in which we can investigate plant reproduction at the cellular and molecular level, such that much progress can be expected in the near future.

\section{References}

Amien S, Kliwer I, Márton ML, Debener T, Geiger D, Becker D, Dresselhaus T (2010) Defensin-like ZmES4 mediates pollen tube burst in maize via opening of the potassium channel KZM1. PLoS Biol 8:e1000388

Armenta-Medina A, Demesa-Arévalo E, Vielle-Calzada JP (2011) Epigenetic control of cell specification during female gametogenesis. Sex Plant Reprod. doi:10.1007/s00497-011-0166-z (this issue)

Autran D, Baroux C, Raissig MT, Lenormand T, Wittig M, Grob S, Steimer A, Barann M, Klostermeier UC, Leblanc O, VielleCalzada J-P, Rosenstiel P, Grimanelli D, Grossniklaus U (2011) Maternal epigenetic pathways control parental contributions to Arabidopsis early embryogenesis. Cell (in press)

Bastock R, St Johnston D (2008) Drosophila oogenesis. Curr Biol 18:R1082-R1087

Bayer M, Nawy T, Giglione C, Galli M, Meinnel T, Lukowitz W (2009) Paternal control of embryonic patterning in Arabidopsis thaliana. Science 323:1485-1488

Bemer M, Wolters-Arts M, Grossniklaus U, Angenent GC (2008) The MADS domain protein DIANA acts together with AGAMOUSLIKE80 to specify the central cell in Arabidopsis ovules. Plant Cell 20:2088-2101

Bencivenga S, Colombo L, Masiero S (2011) Cross talk between the sporophyte and the megagametophyte during ovule development. Sex Plant Reprod. doi:10.1007/s00497-011-0162-3 (this issue)

Borges F, Gomes G, Gardner R, Moreno N, McCormick S, Feijó JA, Becker JD (2008) Comparative transcriptomics of Arabidopsis sperm cells. Plant Physiol 148:1168-1181

Chitwood DH, Timmermans MC (2010) Small RNAs are on the move. Nature 467:415-419
Dresselhaus T, Márton ML (2009) Micropylar pollen tube guidance and burst: adapted from defense mechanisms? Curr Opin Plant Biol 12:773-780

Dresselhaus T, Lausser A, Márton ML (2011) Using maize as a model to study pollen tube growth and guidance, cross-incompatibility and sperm delivery in grasses. Ann Bot (in press)

Escobar-Restrepo JM, Huck N, Kessler S, Gagliardini V, Gheyselinck J, Yang WC, Grossniklaus U (2007) The FERONIA receptorlike kinase mediates male-female interactions during pollen tube reception. Science 317:656-660

Gou X, Yuan T, Wei X, Russell SD (2009) Gene expression in the dimorphic sperm cells of Plumbago zeylanica: transcript profiling, diversity, and relationship to cell type. Plant J 60:33-47

Groß-Hardt R, Kägi C, Baumann N, Moore JM, Baskar R, Gagliano WB, Jürgens G, Grossniklaus U (2007) LACHESIS restricts gametic cell fate in the female gametophyte of Arabidopsis. PLoS Biology 5:e47

Grossniklaus U (2009) PLANT SCIENCE: paternal patterning cue. Science 323:1439-1440

Grossniklaus U, Schneitz K (1998) The molecular and genetic basis of ovule and megagametophyte development. Sem Cell Devel Biol 9:227-238

Hallmann A (2011) Evolution of reproductive development in the volvocine algae. Sex Plant Reprod. doi:10.1007/s00497-0100158-4 (this issue)

Hamamura Y, Saito C, Awai C, Kurihara D, Miyawaki A, Nakagawa T, Kanaoka MM, Sasaki N, Nakano A, Berger F, Higashiyama T (2011) Live-cell imaging reveals the dynamics of two sperm cells during double fertilization in Arabidopsis thaliana. Curr Biol 21:497-502

Heslop-Harrison J (1979) The forgotten generation: some thoughts on the genetics and physiology of angiosperm gametophytes. In: The Bateson lecture: Proceedings of the fourth John Innes symposium, pp 1-14

Johnston AJ, Meier P, Gheyselinck J, Wuest SE, Federer M, Schlagenhauf E, Becker JD, Grossniklaus U (2007) Genetic subtraction profiling identifies genes essential for Arabidopsis reproduction and reveals interaction between the female gametophyte and the maternal sporophyte. Genome Biol 8(10):R204

Johri BM (1985) Embryology of angiosperms. Springer, Berlin, Germany

Kägi C, Baumann N, Nielsen N, Stierhof YD, Groß-Hardt R (2010) The gametic central cell of Arabidopsis determines the lifespan of adjacent accessory cells. Proc Natl Acad Sci USA 107:22350-22355

Kessler SA, Shimosato-Asano H, Keinath NF, Wuest SE, Ingram G, Panstruga R, Grossniklaus U (2010) Conserved molecular components for pollen tube reception and fungal invasion. Science 330:968-971

Kölreuter JG (1761) Vorläufige Nachricht von einigen das Geschlecht der Pflanzen betreffenden Versuchen und Beobachtungen. Gleditschische Handlung, Leipzig

Köszegi D, Johnston AJ, Rutten T, Czihal A, Altschmied L, Kumlehn J, Wuest SE, Kirioukhova O, Gheyselinck J, Grossniklaus U, Bäumlein H (2011) Members of the RKD transcription factor family induce an egg cell-like gene expression program. Plant $\mathbf{J}$ (in press)

Ma H, Sundaresan V (2010) Development of flowering plant gametophytes. Curr Top Dev Biol 91:379-412

Márton ML, Cordts S, Broadhvest J, Dresselhaus T (2005) Micropylar pollen tube guidance by egg apparatus1 of maize. Science 307:573-576

Negbi M (1995) Male and female in Theophrastus's botanical works. J Hist Biol 28:317-332

Nonomura K, Miyoshi K, Eiguchi M, Suzuki T, Miyao A, Hirochika $\mathrm{H}$, Kurata N (2003) The MSP1 gene is necessary to restrict the 
number of cells entering into male and female sporogenesis and to initiate anther wall formation in rice. Plant Cell 15:1728-1739

Okuda S, Higashiyama T (2010) Pollen tube guidance by attractant molecules: LUREs. Cell Struct Funct 35:45-52

Okuda S, Tsutsui H, Shiina K, Sprunck S, Takeuchi H, Yui R, Kasahara RD, Hamamura Y, Mizukami A, Susaki D, Kawano N, Sakakibara T, Namiki S, Itoh K, Otsuka K, Matsuzaki M, Nozaki H, Kuroiwa T, Nakano A, Kanaoka MM, Dresselhaus T, Sasaki $\mathrm{N}$, Higashiyama $\mathrm{T}$ (2009) Defensin-like polypeptide LUREs are pollen tube attractants secreted from synergid cells. Nature 458:357-361

Olmedo-Monfil V, Durán-Figueroa N, Arteaga-Vázquez M, DemesaArévalo E, Autran D, Grimanelli D, Slotkin RK, Martienssen RA, Vielle-Calzada J-P (2010) Control of female gamete formation by a small RNA pathway in Arabidopsis. Nature 464:628-632

Pagnussat GC, Yu H-J, Sundaresan V (2007) Cell-fate switch of synergid to egg cell in Arabidopsis eostre mutant embryo sacs arises from misexpression of the BEL1-Like Homeodomain gene BLH1. Plant Cell 19:3578-3592

Pagnussat GC, Alandete-Saez M, Bowman JL, Sundaresan V (2009) Auxin-dependent patterning and gamete specification in the Arabidopsis female gametophyte. Science 324:1684-1689

Pillot M, Baroux C, Vazquez MA, Autran D, Leblanc O, Vielle-Calzada JP, Grossniklaus U, Grimanelli D (2010) Embryo and endosperm inherit distinct chromatin and transcriptional states from the female gametes in Arabidopsis. Plant Cell 22:307-332

Russell SD, Gou X, Wei X, Yuan T (2010) Male gamete biology in flowering plants. Biochem Soc Trans 38:598-603
Sheridan WF, Avalkina NAA, Shamrov II, Batygina TB, Golubovskaya IN (1996) The macl gene: controlling the commitment to the meiotic pathway in maize. Genetics 142:1009-1020

Singh M, Goel S, Meeley RB, Dantec C, Parrinello H, Michaud C, Leblanc O, Grimanelli D (2011) Production of viable gametes without meiosis in maize deficient for an ARGONAUTE protein. Plant Cell 23:443-458

Slotkin RK, Vaughn M, Borges F, Tanurdzic M, Becker JD, Feijó JA, Martienssen RA (2009) Epigenetic reprogramming and small RNA silencing of transposable elements in pollen. Cell 136:461-472

Sprunck S, Groß-Hardt R (2011) Nuclear behavior, cell polarity, and cell specification in the female gametophyte. Sex Plant Reprod. doi:10.1007/s00497-011-0161-4 (this issue)

Steffen JG, Kang I-H, Portereiko MF, Lloyd A, Drews GN (2008) AGL61 interacts with AGL80 and is required for central cell development in Arabidopsis. Plant Physiol 148:259-268

Twell D (2011) Male gametogenesis and germline specification in flowering plants. Sex Plant Reprod. doi:10.1007/s00497-0100157-5 (this issue)

Weismann A (1893) The germ-plasm: a theory of heredity. Charles Scribner's Sons, New York

Wuest SE, Vijverberg K, Schmidt A, Weiss M, Gheyselinck J, Lohr M, Wellmer F, Rahnenführer J, von Mering C, Grossniklaus U (2010) Arabidopsis female gametophyte gene expression map reveals similarities between plant and animal gametes. Curr Biol 20:506-512

Zhang Z, Laux T (2011) The asymmetric division of the Arabidopsis zygote: from cell polarity to an embryo axis. Sex Plant Reprod. doi:10.1007/s00497-010-0160-x (this issue) 